Journal of Patient-Centered

Volume 2

Issue 3 - Vascular Disease

Article 1

8-14-2015

\title{
Vascular Medicine: A ‘Primary’ Specialty
}

Mark W. Mewissen

Follow this and additional works at: https://aah.org/jpcrr

Part of the Cardiovascular Diseases Commons, Circulatory and Respiratory Physiology Commons, and the Radiology Commons

\section{Recommended Citation}

Mewissen MW. Vascular medicine: a 'primary' specialty. J Patient-Centered Res Rev. 2015;2:85-86. doi: $10.17294 / 2330-0698.1213$

Published quarterly by Midwest-based health system Advocate Aurora Health and indexed in PubMed Central, the Journal of Patient-Centered Research and Reviews (JPCRR) is an open access, peer-reviewed medical journal focused on disseminating scholarly works devoted to improving patient-centered care practices, health outcomes, and the patient experience. 


\title{
Vascular Medicine: A ‘Primary’ Specialty
}

\author{
Mark W. Mewissen, MD | Message from the Guest Editor \\ Aurora Health Care Vascular Center, Milwaukee, WI
}

Patients who suffer from vascular diseases present to their primary care physicians with an assortment of some of the most complex signs and symptoms. Continued advances in the diagnosis and treatment strategies at hand will undoubtedly result in improved lifestyle and prolonged survival for many. In this special themed issue of Journal of Patient-Centered Research and Reviews, for which I had the honor to serve as guest editor, our contributing authors address some of the latest advances in vascular medicine, thereby providing an educational and well-rounded snapshot of the current state of this important and everevolving field.

Not all patients should be initially subjected to expensive imaging tests such as computed tomography (CT) or magnetic resonance imaging. Duplex ultrasound has proved an indispensible and cheaper diagnostic tool that is readily available to all. In this issue, Fish et al. provide a comprehensive review of its current role not only for initial diagnosis, but also for surveillance of patients who have undergone complex revascularization procedures. ${ }^{1}$

The subclavian vein has become a routine percutaneous entry site to insert a variety of cardiac devices. Although such procedures are lifesaving for many patients, the clinical presentation of arm swelling and pain that may result is not innocuous and is usually the result of a stenosis at the cardiac device entry site, or even complete thrombosis of the subclavian vein. In an extensive and comprehensive review of this important topic, Drs. Brian O'Leary and Suhail Allaqaband offer a well-illustrated safe and effective treatment using balloon angioplasty and stenting. ${ }^{2}$

Correspondence: Mark W. Mewissen, MD, 2801 W. Kinnickinnic River Parkway, Suite 330, Milwaukee, WI, 53215, T: 414-385-2429, F: 414-385-2461, Email:

mark.mewissen@aurora.org

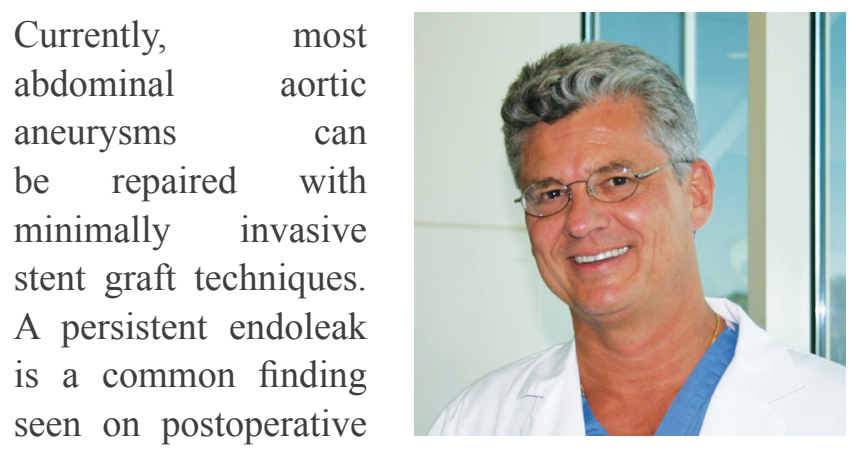
surveillance CT scans that can pose a challenge for best management. For instance, can such an ailment be safely watched or should it be treated? And if treatment is recommended, what is the optimal strategy? On page 118, we review the contemporary management of endoleaks in addition to illustrating an innovative treatment technique that should capably equip interventionalists with a new approach for treating some of the most complex endoleaks. $^{3}$

Liver transplantation is a common surgical procedure that can be complicated by stenosis at the hepatic arterial anastomosis. This potentially life-threatening condition can now be safely treated with low-profile guidewires and stent delivery catheters, obviating the need for difficult and high-risk open corrective surgery. On page 127, Parmar et al. describe in step-by-step detail how many tools developed for percutaneous coronary interventions also can be safely and effectively used in noncoronary vascular territories. ${ }^{4}$

One can clearly see the wide range of diseases, clinical presentations and anatomical regions that bridge the vascular sphere. Another serious health condition is aortic dissection, which mandates immediate diagnosis and treatment. In his review of changing paradigms in the treatment of acute type B aortic dissections, Dr. Eric Weiss discusses how newer endovascular treatment strategies are best used to optimize management. ${ }^{5}$ Likewise, novel oral anticoagulants are becoming popular management options for stroke prophylaxis in 
atrial fibrillation, deep vein thrombosis and pulmonary embolism treatment and prophylaxis; on page 139, Dr. Laith Alsayegh provides a comprehensive review of these new agents and helps sort out their benefits and best indications. ${ }^{6}$

In addition to comprehensive review articles addressing some of the latest innovations and options for diagnosis and treatment of vascular diseases, this issue also features an original research study ${ }^{7}$ and accompanying editorial ${ }^{8}$ reporting the respective merits of bypass graft surgery and angioplasty using drug-eluting stents in treating high-risk patients with coronary artery disease, a contemporary topic of debate among interventional cardiologists and cardiac surgeons.

As a vascular specialist, it is my hope this special issue will help enhance the care of the many patients who suffer from vascular diseases. It has been an honor to work with Editor-in-Chief Dennis Baumgardner and his support staff. We are deeply indebted to all who have so expertly contributed to this issue of Journal of Patient-Centered Research and Reviews.

\section{REFERENCES}

1. Fish JH 3rd, Klein-Weigel P, Fraedrich G. Overview of the role of duplex ultrasound for treatment and surveillance of peripheral arterial disease. J Patient-Centered Res Rev. 2015;2:104-11.

2. O'Leary B, Allaqaband S. Subclavian vein stenosis/occlusion following transvenous cardiac pacemaker and defibrillator implantation: incidence, pathophysiology and current management. J Patient-Centered Res Rev. 2015;2:112-7.

3. Jan MF, Mewissen MW. Type II endoleak following endovascular repair of infrarenal abdominal aortic aneurysm: innovative transgraft approach to contemporary management. J Patient-Centered Res Rev. 2015;2:118-26.

4. Parmar H, Beard R, Mewissen MW, Shaikh A, Bajwa T. Use of coronary techniques in celiac and hepatic artery stenting in post-hepatic transplant patients. $J$ Patient-Centered Res Rev. 2015;2:127-31.

5. Weiss ES. New paradigms in the treatment of acute complicated and uncomplicated type B aortic dissection. J Patient-Centered Res Rev. 2015;2:132-8.

6. Alsayegh L. Novel oral anticoagulants for stroke prophylaxis and venous thromboembolism prevention and treatment. J Patient-Centered Res Rev. 2015;2:139-46.

7. Nfor T, Shetabi K, Hassan W, et al. Clinical outcomes after drug-eluting stents versus coronary artery bypass surgery in high surgical risk patients with left main or three-vessel coronary artery disease. $J$ Patient-Centered Res Rev. 2015;2:95-103.

8. Jan MF. A tale of two techniques: demystifying the myth. J Patient-Centered Res Rev. 2015;2:87-94.

(C) 2015 Aurora Health Care, Inc. 